\title{
openheart Coenzyme Q10 for the treatment of heart failure: a review of the literature
}

\author{
James J DiNicolantonio, ${ }^{1}$ Jaikrit Bhutani, ${ }^{2}$ Mark F McCarty, ${ }^{3}$ James H O'Keefe ${ }^{1}$
}

To cite: DiNicolantonio JJ, Bhutani J, McCarty MF, et al. Coenzyme Q10 for the treatment of heart failure: a review of the literature. Open Heart 2015;2:e000326. doi:10.1136/openhrt-2015000326

Received 7 August 2015 Revised 23 September 2015 Accepted 29 September 2015

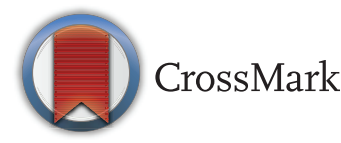

\footnotetext{
${ }^{1}$ Saint Luke's Mid America Heart Institute, Kansas City, Missouri, USA

${ }^{2} \mathrm{Pt}$ BD Sharma PGIMS,

Rohtak, Haryana, India

${ }^{3}$ Catalytic Longevity,

Encinitas, California, USA
}

Correspondence to Dr James J DiNicolantonio; jjdinicol@gmail.com

\section{ABSTRACT}

Coenzyme Q10 (CoQ10) is an endogenously synthesised and diet-supplied lipid-soluble cofactor that functions in the mitochondrial inner membrane to transfer electrons from complexes I and II to complex III. In addition, its redox activity enables CoQ10 to act as a membrane antioxidant. In patients with congestive heart failure, myocardial CoQ10 content tends to decline as the degree of heart failure worsens. A number of controlled pilot trials with supplemental CoQ10 in heart failure found improvements in functional parameters such as ejection fraction, stroke volume and cardiac output, without side effects. Subsequent meta-analyses have confirmed these findings, although the magnitude of benefit tends to be less notable in patients with severe heart failure, or within the context of ACE inhibitor therapy. The multicentre randomised placebo-controlled Q-SYMBIO trial has assessed the impact of supplemental CoQ10 on hard endpoints in heart failure. A total of 420 patients received either CoQ10 (100 mg three times daily) or placebo and were followed for 2 years. Although short-term functional endpoints were not statistically different in the two groups, CoQ10 significantly reduced the primary long-term endpointa major adverse cardiovascular event-which was observed in $15 \%$ of the treated participants compared to $26 \%$ of those receiving placebo ( $\mathrm{HR}=0.50, \mathrm{Cl} 0.32$ to $0.80, p=0.003$ ). Particularly in light of the excellent tolerance and affordability of this natural physiological compound, supplemental CoQ10 has emerged as an attractive option in the management of heart failure, and merits evaluation in additional large studies.

\section{INTRODUCTION}

Heart failure occurs due to failure of the heart to pump adequately (systolic dysfunction) and/or impaired relaxation (diastolic dysfunction). Among a variety of causes, coronary artery disease, hypertension, cardiomyopathy, ageing, valvular heart disease and congenital heart disease are the most common. ${ }^{1}$ Statistical data from the American Heart Association (AHA) show that a total of 5.1 million people in the USA suffer from heart failure, ${ }^{2}$ while 23 million people have diagnosed heart failure worldwide. ${ }^{3}$ Morbidity and mortality due to heart failure increase with age, ${ }^{4}$ and it is reported that heart failure is responsible for one in nine deaths in the USA. ${ }^{2}$ Moreover, heart failure is among the most frequent causes of hospitalisations and disability in the elderly. ${ }^{5}{ }^{6}$ Though there have been major improvements in pharmacological management of heart failure, mortality rates continue to exceed $10 \%$ per year, reaching between $20 \%$ to $50 \%$ in severe cases. ${ }^{7}$

Recently, long-term therapy with coenzyme Q10 (CoQ10) has been shown to improve heart failure symptoms, reduce major adverse cardiovascular events (MACE) and mortality, and to be safe and well tolerated. ${ }^{8}$ This review covers the existing literature pertaining to CoQ10 and the treatment of heart failure.

\section{ROLE OF COQ10 IN HEART FAILURE (HF)}

A benzoquinone derivative with an isoprenoid side chain, CoQ10 was first isolated from beef heart mitochondria. ${ }^{9}$ It exists in a reduced (ubiquinol, CoQ10H2) as well as in an oxidised (ubiquinone, CoQ10) form. It is a lipophilic molecule and uses lipoproteinmediated transport for circulation; thus, plasma levels of CoQ10 correlate with plasma total and low-density-lipoprotein (LDL) cholesterol. ${ }^{10-17}$ Along with dietary intake from meat products, CoQ10 is also synthesised endogenously. ${ }^{18}$ It acts as an essential cofactor in oxidative phosphorylation in mitochondria, having a key role in formation of ATP. It mediates electron transfer in the electron transport chain (ETC) from complex 1 (NADH coenzyme $Q$ reductase) to complex 3 (cytochrome bc1 complex), and from complex 2 (succinate dehydrogenase) to complex 3. Additionally, CoQ10 has direct antioxidant effects, preventing membrane oxidation and lipid peroxidation, stabilising LDL particles, and promoting recycling of $\alpha$-tocopherol, thereby supporting cardiovascular health. $^{19-22}$

CoQ10 is a key component in the mitochondrial ETC for ATP generation, and exists in abundance in the myocardium, as 
compared to other tissues. ${ }^{18}$ Myocardial CoQ10 depletion has been postulated as a mechanism in development and progression of congestive heart failure (CHF). Folkers $e t a l^{23}$ demonstrated that myocardial CoQ10 level was linked with symptomatic severity of CHF, with the lowest levels observed in patients of New York Heart Association (NYHA) class IV and the highest levels in patients in NYHA class I. Additionally, CoQ10, through its antioxidant effects, may reduce oxidative stress, which is known to adversely affect left ventricular ejection fraction and alter disease outcomes. ${ }^{24}$ Lastly, CoQ10 may stabilise calcium-dependent channels in the myocardium, enhancing effective ATP synthesis. ${ }^{25}$

Frequently, statins and $\beta$-blockers are used in patients of CHF for prevention of cardiovascular comorbidities. These drugs have been found to decrease CoQ10 levels by inhibiting the mevalonate pathway and myocardial enzymes, respectively. ${ }^{26-28}$ In an observational study by Molyneux et $a l,{ }^{29}$ it was shown that CoQ10 is an independent predictor of survival, whether dichotomised at the receiver operating characteristic curve cut-point (HR 2.0; $95 \%$ CI 1.2 to 3.3 ) or the median (HR 1.6; $95 \%$ CI 1.0 to 2.6); these findings persisted after adjustment for serum cholesterol level. Additionally, myocardial coenzyme Q10 levels in patients with chronic HF were found to be $33 \%$ lower as opposed to levels in control patients. ${ }^{30} 31$ The aforementioned evidence suggests that CoQ10 may be useful in patients with CHF by replenishing deficient levels, which may improve ATP synthesis and left ventricular function.

The reference range of reduced CoQ10 for children (younger than 18 years of age) is $320-1376 \mu \mathrm{g} / \mathrm{L}$ and for adults (aged 18 years or older) it is $415-1480 \mu \mathrm{g} / \mathrm{L}$. The reference values for total CoQ10 for children and adults are $320-1558 \mu \mathrm{g} / \mathrm{L}$ and $433-1532 \mu \mathrm{g} / \mathrm{L}$, respectively. The normal percentage of reduced CoQ10 in children varies from $93 \%$ to $100 \%$, while in adults it falls between $92 \%$ and $98 \% .^{32}$

\section{FORMULATIONS OF COQ10}

CoQ10, being water insoluble, is marketed in a variety of formulations that solubilise $\mathrm{CoQ} 10$ and facilitate its absorption. The commonly available preparations are in the forms of powder, tablets, softgel oil suspension capsules and two-piece capsules. These preparations are marketed as crystalline CoQ10 powder, oil emulsions, solubilisates and nanoparticulate CoQ10. The inactive base compounds used in these formulations are selected from Food and Drug Administration (FDA)-recognised safe ingredients. ${ }^{33}$

CoQ10 bioavailability varies with the delivery method. Comparisons between the various studies assessing CoQ10 bioavailability are limited by the use of different doses, dosage timings in relation to meals and time of sample collection. Weis $e t a \vec{l}^{34}$ reported significant differences between different formulations, the highest bioavailability being shown for soybean oil suspension of
CoQ10 (Bioquinon). ${ }^{35}$ Miles et al concluded that, among the solubilised products, the reduced form (Q-Nol or ubiquinol) had more bioavailability as opposed to other fully-solubilised control formulations, and non-solubilised CoQ10 powder was found to have minimal absorption after a $180 \mathrm{mg}$ dose. ${ }^{36-39} \mathrm{In}$ another comparative study of 10 commercially available preparations of CoQ10, the median change in bioavailability obtained with the best brand, Q-Gel, was superior to the other brands, ranging between $182 \%$ and $421 \% .{ }^{37} 40$ Recently, the new water-soluble formulation (PureSorb-Q40) was found to have better uptake than oil-emulsion formulations. ${ }^{41} 42$

Comparisons between colloidal-Q10 and three preparations of CoQ10 (two solubilisates and oil based formulation) showed that the former had better bioavailability, as its mechanism of action was similar to the innate mixed micellar transport system. ${ }^{43}{ }^{44}$ No significant differences have been described among healthy adults for four different oral CoQ10 formulations of a single $600 \mathrm{mg}$ dose. ${ }^{45}$ In summary, the bioavailability of CoQ10 reflects the type and amount of oil in a given preparation, and the delivery method. The increasing order of bioavailability is as follows: powder, oil-emulsioned (eg, Bioquinon), solubilised (eg, Q-Nol) and nanoparticulated (eg, PureSorb-Q40).

\section{TRIAL DATA OF COQ10 THERAPY IN HF}

There have been numerous observational reports in the last few decades reporting the usefulness of CoQ10 in improving HF symptoms, including ejection fraction, left ventricular size and quality of life. However, these studies had several design shortcomings, which have prevented their translation into clinical practice. ${ }^{46-53}$

Several clinical trials report comparisons of CoQ10 efficacy versus placebo. While some report no advantage over placebo, others conclude that CoQ10 supplementation improves systolic function and reduces ventricular size. ${ }^{54-66}$ Thus, due to small sample sizes and concomitant large effect sizes in these trials, it may be difficult to make certain statements regarding advantages and disadvantages of CoQ10 therapy. Also, it is difficult to assess the benefits of CoQ10 with respect to severity and aetiology of HF, and to segregate responders versus nonresponders. Subsequently, to overcome these limitations, the trial data were pooled using meta-analysis to better understand the benefits of CoQ10 therapy.

Initial meta-analysis by Soja and Mortensen ${ }^{67}$ reported that, compared to HF patients in the placebo group, patients treated with CoQ10 achieved a better ejection fraction, stroke volume, cardiac output, cardiac index and end diastolic volume index $(92 \%(\mathrm{p}<0.0001), 76 \%$ $(p<0.005), 73 \% \quad(p<0.05), 87 \% \quad(p<0.0001)$ and $88 \%$ $(\mathrm{p}<0.0001)$, respectively). In another analysis by Sander et al, with CoQ10 doses ranging from $60-200 \mathrm{mg} /$ day, it was shown that there was a $3.7 \%$ net improvement in ejection fraction (1.59 to $5.77 ; \mathrm{p}<0.00001)$. Cardiac 
output improved by an average of $0.28 \mathrm{~L} / \mathrm{min}(0.03$ to 0.53; $\mathrm{p}=0.96$ ). Also, an increasing trend was demonstrated in stroke volume and stroke index, which increased by an average of $5.68 \mathrm{~mL} / \mathrm{m}^{2}$ (1.02 to $10.34 ; \mathrm{p}=0.28$ ). Further subgroup analysis revealed that ejection fraction improved by $6.74 \%$ (CI $2.63 \%$ to $10.86 \%$ ) without angiotensin converting enzyme inhibitor (ACEi) therapy as compared to a mere $1.16 \%$ change (CI $-0.39 \%$ to $2.71 \%$ ) with use of ACEI. ${ }^{68}$ Another subgroup analysis showed that ejection fraction improved by $3.69 \%$ (CI $2.30 \%$ to $5.07 \%$ ) when patients with severe HF (NYHA IV) were excluded, as compared to $2.17 \%$ (CI $0.28 \%$ to $4.05 \%$ ) improvement in the absence of such exclusion, ${ }^{68}$ suggesting that initiating CoQ10 therapy early could help salvage cardiac myocyte function.

Fotino et al reported similar results in a meta-analysis; CoQ10 supplementation resulted in a pooled mean net increase in ejection fraction of $3.67 \%$ (95\% CI $1.60 \%$ to $5.74 \%, \mathrm{p}<0.001)$. A post hoc subgroup analysis showed change in ejection fraction was significant for participants with a baseline $\geq 30 \%$ (net change: 4.82 ; $95 \%$ CI 3.01 to 6.59), but was not significant for participants with a baseline $<30 \%$ (net change: $0.40 ; 95 \%$ CI -0.91 to 1.70 ), further suggesting the benefits of early CoQ10 therapy. ${ }^{69}$

These meta-analyses hence suggest that supplemental CoQ10 can confer functional benefits in heart failure, but that these benefits tend to be greater in the absence of concurrent ACEI therapy and in patients with less severe dysfunction. These limitations may explain the failure of some modest-sized studies to confirm benefit for CoQ10.

Another possible benefit of CoQ10 supplementation may be its ability to improve exercise capacity in those treated with statins. ${ }^{70}$ As exercise capacity is a strong predictor of prognosis, this might be another advantage of CoQ10 supplementation. ${ }^{71}$

Despite favourable effects on surrogate endpoints with CoQ10 supplementation, the impact of CoQ10 on hard endpoints in HF, such as mortality, has long remained unclear. Fortunately, more clarity in this respect was provided with the recently released results from the Q-SYMBIO trial, a prospective, randomised, doubleblind, placebo-controlled, multicentre trial of CoQ10 as adjunctive treatment of chronic HF, focusing on changes in symptoms, biomarker status and long-term outcomes. This trial included 420 patients with moderate to severe CHF, who were randomly assigned to receive, for a 2-year period, CoQ10 $100 \mathrm{mg}$ three times daily $(\mathrm{n}=202)$ or placebo $(n=218)$, as an adjunct to standard therapy. No significant differences were observed for secondary end points (NYHA functional class, visual analogue scale score for dyspnoea, fatigue and improvement in symptoms, $N$-terminal pro-brain natriuretic polypeptide (NT-proBNP) and 6 min walk test) between two groups at 16 weeks. However, on analysing long-term primary end points with an intention to treat analysis at week 106 , there was a significant reduction in MACE in the CoQ10 group ( $15 \%, \mathrm{n}=30$ vs $26 \%, \mathrm{n}=57$; corresponding to relative reduction of $43 \%$ with $\mathrm{p}=0.005$; with $\mathrm{HR} 0.50$; $95 \%$ CI 0.32 to $0.80 ; \mathrm{p}=0.003$ calculated from a Cox regression analysis stratified by centre). Additionally, the secondary endpoints at week 106 were better in the CoQ10 group-NYHA class improvement by 1 grade (58\%, $\mathrm{n}=86$ vs $45 \%, \mathrm{n}=68 ; \mathrm{p}=0.028)$ and serum NT-proBNP reduction $(60 \%, 1137 \mathrm{pg} / \mathrm{mL}$ vs $52 \%$, $881 \mathrm{pg} / \mathrm{mL} ; \mathrm{p}>0.05)$. The patients in the CoQ10 group had significantly fewer cardiovascular deaths $(9 \%, \mathrm{n}=18$ vs $16 \%, \mathrm{n}=34$; corresponding to $43 \%$ relative reduction with $\mathrm{p}=0.039$; with HR $0.51 ; 95 \%$ CI 0.28 to 0.92 ; $\mathrm{p}=0.026$ calculated from a Cox regression analysis stratified by centre) and hospital stays for heart failure $(8 \%$, $\mathrm{n}=17$ vs $14 \%, \mathrm{n}=31$, HR $0.51 ; 95 \%$ CI 0.27 to 0.95 ; $\mathrm{p}=0.033)$. Also, in the CoQ10 group there were significantly fewer all-cause deaths reported $(10 \%, \mathrm{n}=21$ vs $18 \%, \mathrm{n}=39$; corresponding to $42 \%$ relative reduction with $\mathrm{p}=0.036$; with $\mathrm{HR} 0.51 ; 95 \%$ CI 0.30 to 0.89 ; $\mathrm{p}=0.018$ calculated from a Cox regression analysis stratified by centre). Additionally, the number of adverse events tended to be less in the CoQ10 group (13\%, $\mathrm{n}=26$ vs $19 \%, \mathrm{n}=41 ; \mathrm{p}=0.110){ }^{8}$

In summary, the long-term supplementation of CoQ10 in patients of HF seems safe, appears to produce symptomatic improvements, and, more importantly, has been found to significantly reduce MACEs and mortality. Larger randomised studies will be needed to confirm the results of the Q-SYMBIO trial in patients with HF.

\section{CONCLUSION}

The relationship of CoQ10 status to congestive heart failure has been studied in patients for decades. Early studies reported that myocardial levels of CoQ10 tended to decline with increasing severity of heart failure. Such a decline might be exacerbated by concurrent treatment with statins and $\beta$-blockers, which can suppress endogenous CoQ10 synthesis. Pilot supplementation trials with CoQ10 in HF patients reported improvements in functional parameters such as ejection fraction, stroke volume and cardiac output, with minimal side effects. These findings were reinforced by subsequent meta-analyses, which further concluded that benefits tended to be greater in earlier stage $\mathrm{HF}$ and in patients not treated with ACEIs. Moreover, it was found that in-hospital plasma CoQ10 in HF patients correlated inversely with subsequent mortality. Most definitively, the very recent Q-SYMBIO trial, a multicentre randomised placebo-controlled trial, has demonstrated the beneficial impact of supplemental CoQ10 on hard end points in HF. Thus, in aggregate, evidence suggests that supplemental CoQ10 may be a useful option for effective management of heart failure, with the advantage of excellent clinical tolerance-reflecting its status as an essential physiological cofactor.

Competing interests JJD works for a company that sells CoQ10 but he does not directly profit from their sales. MFM is owner and science director of a nutraceutical company, of which one product is a CoQ10 supplement. JHO is 
part owner and founder of CardioTabs, a nutraceutical company that markets a CoQ10 supplement as one of its products.

Provenance and peer review Not commissioned; externally peer reviewed.

Data sharing statement No additional data are available.

Open Access This is an Open Access article distributed in accordance with the Creative Commons Attribution Non Commercial (CC BY-NC 4.0) license, which permits others to distribute, remix, adapt, build upon this work noncommercially, and license their derivative works on different terms, provided the original work is properly cited and the use is non-commercial. See: http:// creativecommons.org/licenses/by-nc/4.0/

\section{REFERENCES}

1. Mann DL, Chakinala M. Chapter 234. Heart failure and Cor Pulmonale. In: Longo DL, Fauci AS, Kasper DL, et al., eds. Harrison's principles of internal medicine. 18th edn. New York, NY: The McGraw-Hill Companies, 2012.

2. Go AS, Mozaffarian D, Roger VL, et al. Heart disease and stroke statistics-2014 update: a report from the American Heart Association. Circulation 2014;129:e28-292.

3. McMurray JJ, Petrie MC, Murdoch DR, et al. Clinical epidemiology of heart failure: public and private health burden. Eur Heart $J$ 1998;19 (Suppl P):P9-16.

4. Rodríguez-Artalejo F, Banegas Banegas JR, Guallar-Castillón P. Epidemiology of heart failure. Revista Española de Cardiología (English Version) 2004;57:163-70.

5. Deedwania PC, Carbajal EV. Chapter 18. Congestive heart failure. In: Crawford MH, ed. CURRENT diagnosis \& treatment: cardiology. 3rd edn. New York, NY: The McGraw-Hill Companies, 2009.

6. Massie BM, Shah NB. Evolving trends in the epidemiologic factors of heart failure: rationale for preventive strategies and comprehensive disease management. Am Heart $J$ 1997;133:703-12.

7. Ho KK, Pinsky JL, Kannel WB, et al. The epidemiology of heart failure: the Framingham Study. J Am Coll Cardiol 1993;22(4 Suppl A):6a-13a.

8. Mortensen SA, Rosenfeldt F, Kumar A, et al. The effect of coenzyme Q10 on morbidity and mortality in chronic heart failure: results from Q-SYMBIO: a randomized double-blind trial. JACC Heart Fail 2014;2:641-9.

9. Crane FL, Hatefi $\mathrm{Y}$, Lester RL, et al. Isolation of a quinone from beef heart mitochondria. Biochim Biophys Acta 1957;25:220-1.

10. Edlund PO. Determination of coenzyme Q10, $\alpha$-tocopherol and cholesterol in biological samples by coupled-column liquid chromatography with coulometric and ultraviolet detection. J Chromatogr 1988;425:87-97.

11. Menke T, Niklowitz P, de Sousa G, et al. Comparison of coenzyme Q10 plasma levels in obese and normal weight children. Clin Chim Acta 2004;349:121-7.

12. Wolters M, Hahn A. Plasma ubiquinone status and response to six-month supplementation combined with multivitamins in healthy elderly women-results of a randomized, double-blind, placebo-controlled study. Int J Vitam Nutr Res 2003;73:207-14.

13. Tomasetti M, Littarru GP, Stocker R, et al. Coenzyme Q10 enrichment decreases oxidative DNA damage in human lymphocytes. Free Radic Biol Med 1999;27:1027-32.

14. Lagendijk J, Ubbink JB, Vermaak WJ. Measurement of the ratio between the reduced and oxidized forms of coenzyme Q10 in human plasma as a possible marker of oxidative stress. J Lipid Res 1996;37:67-75.

15. Kaikkonen J, Nyyssönen K, Tuomainen TP, et al. Determinants of plasma coenzyme Q10 in humans. FEBS Lett 1999;443:163-6.

16. Kontush A, Reich A, Baum K, et al. Plasma ubiquinol-10 is decreased in patients with hyperlipidaemia. Atherosclerosis 1997;129:119-26.

17. Molyneux SL, Florkowski CM, Lever M, et al. Biological variation of coenzyme Q10. Clin Chem 2005;51:455-7.

18. Weber C, Bysted A, Hllmer G. The coenzyme Q10 content of the average Danish diet. Int J Vitam Nutr Res 1997;67:123-9.

19. Sohal RS. Coenzyme $Q$ and vitamin E interactions. Methods Enzymol 2004;378:146-51.

20. Mohr D, Bowry VW, Stocker R. Dietary supplementation with coenzyme Q10 results in increased levels of ubiquinol-10 within circulating lipoproteins and increased resistance of human low-density lipoprotein to the initiation of lipid peroxidation. Biochim Biophys Acta 1992;1126:247-54.

21. Stocker R, Bowry VW, Frei B. Ubiquinol-10 protects human low density lipoprotein more efficiently against lipid peroxidation than does alpha-tocopherol. Proc Natl Acad Sci USA 1991;88:1646-50.
22. Mellors A, Tappel AL. The inhibition of mitochondrial peroxidation by ubiquinone and ubiquinol. J Biol Chem 1966;241:4353-6.

23. Folkers K, Vadhanavikit S, Mortensen SA. Biochemical rationale and myocardial tissue data on the effective therapy of cardiomyopathy with coenzyme Q10. Proc Natl Acad Sci USA 1985;82:901-4.

24. Belch JJ, Bridges $A B$, Scott $N$, et al. Oxygen free radicals and congestive heart failure. Br Heart J 1991;65:245-8.

25. Tsutsui T, Tsutamoto T, Wada A, et al. Plasma oxidized low-density lipoprotein as a prognostic predictor in patients with chronic congestive heart failure. J Am Coll Cardiol 2002;39:957-62.

26. Folkers K, Langsjoen $\mathrm{P}$, Willis $\mathrm{R}$, et al. Lovastatin decreases coenzyme Q levels in humans. Proc Natl Acad Sci USA 1990;87:8931-4.

27. Berthold HK, Naini A, Di Mauro S, et al. Effect of ezetimibe and/or simvastatin on coenzyme Q10 levels in plasma: a randomised trial. Drug Saf 2006;29:703-12.

28. Kishi T, Watanabe T, Folkers K. Bioenergetics in clinical medicine $\mathrm{XV}$. Inhibition of coenzyme Q10-enzymes by clinically used adrenergic blockers of beta-receptors. Res Commun Chem Pathol Pharmacol 1977;17:157-64.

29. Molyneux SL, Florkowski CM, George PM, et al. Coenzyme Q10: an independent predictor of mortality in chronic heart failure. J Am Coll Cardiol 2008;52:1435-41.

30. Mortensen SA, Vadhanavikit S, Muratsu K, et al. Coenzyme Q10: clinical benefits with biochemical correlates suggesting a scientific breakthrough in the management of chronic heart failure. Int $J$ Tissue React 1990;12:155-62.

31. Mortensen SA. Perspectives on therapy of cardiovascular diseases with coenzyme Q10 (ubiquinone). Clin Investig 1993;71(8 Suppl): S116-23.

32. Miles MV, Horn PS, Tang PH, et al. Age-related changes in plasma coenzyme Q10 concentrations and redox state in apparently healthy children and adults. Clin Chim Acta 2004;347:139-44.

33. Villalba JM, Parrado C, Santos-Gonzalez M, et al. Therapeutic use of coenzyme Q10 and coenzyme Q10-related compounds and formulations. Expert Opin Investig Drugs 2010;19:535-54.

34. Weis M, Mortensen S, Rassing M, et al. Bioavailability of four oral coenzyme Q 10 formulations in healthy volunteers. Mol Aspects Med 1994;15:s273-s80.

35. Feher J, Sears G. Ubiguinone-containing composition suitable for promoting enhanced intramitochondrial transportation of ubiquinones and methods of using same. Google patents, 2001

36. Peters SE, Woods DH. Stable aqueous dispersion of nutrients. Google patents, 2002.

37. Chopra RK. Reduced form of Cenzyme $Q$ in high bioavailability stable oral dosage form. Google patents, 2004.

38. Goldman R. Method for enhancing dissolution properties of relatively insoluble dietary supplements and product incorporating same. Google patents, 2000.

39. Miles MV, Horn P, Miles L, et al. Bioequivalence of coenzyme Q 10 from over-the-counter supplements. Nutr Res 2002;22:919-29.

40. Molyneux S, Florkowski C, Lever M, et al. The bioavailability of coenzyme Q10 supplements available in New Zealand differs markedly. N Z Med J 2004;117:U1108.

41. Ikemoto $\mathrm{H}$, Minemura T. Coenzyme q10-containing water-soluble compositions. Google Patents 2007.

42. Nukui $\mathrm{K}$, Yamagishi $\mathrm{T}$, Miyawaki $\mathrm{H}$, et al. Comparison of uptake between PureSorb-Q40 and regular hydrophobic coenzyme Q10 in rats and humans after single oral intake. J Nutr Sci Vitaminol (Tokyo) 2007;53:187-90.

43. Vesifact A. Coenzyme Q10 containing microemulsion preconcentrates and microemulsions. Google patents, 2004.

44. Liu Z-X, Artmann C. Relative bioavailability comparison of different coenzyme Q10 formulations with a novel delivery system. Altern Ther Health Med 2008;15:42-6.

45. Constantinescu R, McDermott MP, Dicenzo R, et al. A randomized study of the bioavailability of different formulations of coenzyme Q10 (ubiquinone). J Clin Pharmacol 2007;47:1580-6.

46. Lampertico M, Comis S. Italian multicenter study on the efficacy and safety of coenzyme Q10 as adjuvant therapy in heart failure. Clin Investig 1993;71:S129-33.

47. Soongswang J, Sangtawesin C, Durongpisitkul K, et al. The effect of coenzyme Q10 on idiopathic chronic dilated cardiomyopathy in children. Pediatr Cardiol 2005;26:361-6.

48. Langsjoen $\mathrm{PH}$, Langsjoen $\mathrm{A}$, Willis $\mathrm{R}$, et al. Treatment of hypertrophic cardiomyopathy with coenzyme Q 10. Mol Aspects Med 1997;18:145-51.

49. Langsjoen $\mathrm{PH}$, Langsjoen $\mathrm{PH}$, Folkers $\mathrm{K}$. Long-term efficacy and safety of coenzyme Q10 therapy for idiopathic dilated cardiomyopathy. Am J Cardiol 1990;65:521-3.

50. Langsjoen $\mathrm{P}$, Folkers $\mathrm{K}$, Lyson $\mathrm{K}$, et al. Effective and safe therapy with coenzyme Q10 for cardiomyopathy. Klin Wochenschr 1988;66:583-90. 
51. Sacher H, Sacher M, Landau S, et al. The clinical and hemodynamic effects of coenzyme Q10 in congestive cardiomyopathy. Am J Ther 1997;4:66-72.

52. Rengo $\mathrm{F}$, Abete $\mathrm{P}$, Landino $\mathrm{P}$, et al. Role of metabolic therapy in cardiovascular disease. Clin Investig 1993;71:S124-S8.

53. Baggio E, Gandini R, Plancher A, et al. Italian multicenter study on the safety and efficacy of coenzyme $Q 10$ as adjunctive therapy in heart failure. Mol Aspects Med 1994;15:s287-94.

54. Judy W, Hall J, Toth $P$, et al. Double blind-double crossover study of coenzyme Q10 in heart failure. Biomed Clin Aspects Coenzyme Q 1986;5:315-23.

55. Schneeberger W, Muller-Steinwachs J, Anda L, et al. A clinical double blind and crossover trial with coenzyme Q10 on patients with cardiac disease. In: Folkers K, Yamamura Y, eds. Biomedical and clinical aspects of coenzyme Q. Vol 5. Amsterdam: Elsevier, 1986:325-33.

56. Judy $\mathrm{W}$, Hall $\mathrm{J}$, Toth $\mathrm{P}$, et al. Imporved long-term survival incoenzyme Q10 treated chronic heart failure patients comparedto conventionally treated patients. In: Folkers K, Littarru G, Yamagami $\mathrm{T}$, eds. Biomedical and clinical aspects of coenzyme $Q$. Amsterdam: Elsevier, 1991:291-8.

57. Serra G, Lissoni F, Piemonti C, et al. Evaluation of CoQ10 in patients with moderate heart failure and chronic stable effort angina. In: Folkers K, Littarru G, Yamagami T, eds. Biomedical and clinical aspects of coenzyme Q. 6. Amsterdam: Elsevier, 1991:327-38.

58. Khatta M, Alexander BS, Krichten CM, et al. The effect of coenzyme Q10 in patients with congestive heart failure. Ann Intern Med 2000;132:636-40.

59. Keogh A, Fenton S, Leslie C, et al. Randomised double-blind, placebo-controlled trial of coenzyme Q10 therapy in class II and III systolic heart failure. Heart Lung Circ 2003;12:135-41.

60. Watson PS, Scalia GM, Galbraith A, et al. Lack of effect of coenzyme $Q$ on left ventricular function in patients with congestive heart failure. J Am Coll Cardiol 1999;33:1549-52.
61. Langsjoen PH, Vadhanavikit S, Folkers K. Response of patients in classes III and IV of cardiomyopathy to therapy in a blind and crossover trial with coenzyme Q10. Proc Natl Acad Sci USA 1985;82:4240-4.

62. Munkholm H, Hansen $\mathrm{HH}$, Rasmussen K. Coenzyme Q10 treatment in serious heart failure. Biofactors 1999;9:285-9.

63. Hofman-Bang C, Rehnqvist N, Swedberg K, et al. Coenzyme Q 10 as an adjunctive in the treatment of chronic congestive heart failure. J Card Fail 1995;1:101-7.

64. Poggesi L, Galanti G, Comeglio M, et al. Effect of coenzyme Q10 on left ventricular function in patients with dilative cardiomyopathy: a medium-term randomized double-blind study versus placebo. Curr Ther Res 1991;49:878-86.

65. Permanetter B, Rössy W, Klein G, et al. Ubiquinone (coenzyme Q10) in the long-term treatment of idiopathic dilated cardiomyopathy. Eur Heart J 1992;13:1528-33.

66. Morisco C, Nappi A, Argenziano L, et al. Noninvasive evaluation of cardiac hemodynamics during exercise in patients with chronic heart failure: effects of short-term coenzyme Q10 treatment. Mol Aspects Med 1994;15:s155-63.

67. Soja AM, Mortensen SA. Treatment of congestive heart failure with coenzyme Q10 illuminated by meta-analyses of clinical trials. $\mathrm{Mol}$ Aspects Med 1997;18:159-68.

68. Sander S, Coleman Cl, Patel AA, et al. The impact of coenzyme Q10 on systolic function in patients with chronic heart failure. J Card Fail 2006;12:464-72.

69. Fotino AD, Thompson-Paul AM, Bazzano LA. Effect of coenzyme Q10 supplementation on heart failure: a meta-analysis. Am J Clin Nutr 2013;97:268-75.

70. Deichmann RE, Lavie CJ, Dornelles AC. Impact of coenzyme Q-10 on parameters of cardiorespiratory fitness and muscle performance in older athletes taking statins. Phys Sportsmed 2012;40:88-95.

71. Lavie CJ, Berra K, Arena R.. Formal cardiac rehabilitation and exercise training programs in heart failure: evidence for substantial clinical benefits. J Cardiopulm Rehabil Prev 2013;33:209-11. 